\title{
Anter Kültürü Tekniği ile Ekmeklik Buğday (Triticum aestivum L.) Melez Populasyonlarından Doubled Haploid Bitkilerin Elde Edilmesi
}

\author{
İsmet BAŞER Kayıhan Z. KORKUT Oğuz BİLGiN *Alpay BALKAN \\ Namık Kemal Üniversitesi Ziraat Fakültesi Tarla Bitkileri Bölümü, Tekirdağ \\ *Sorumlu yazar e-posta (Corresponding author e-mail): abalkan@nku.edu.tr
}

\section{Öz}

Çalışmada, Namık Kemal Üniversitesi Ziraat Fakültesi Tarla Bitkileri Bölümünde elde edilen 17 F2 ekmeklik buğday melez popülasyonu materyal olarak kullanılmıştır. Ekmeklik buğday genotipleride erkenorta tek çekirdekli dönemde çiçek tozu içeren anterler W14 besi ortamında kültüre alınmışlardır. Bu ortamda gelişim gösteren kalluslar ve yeşil bitkicikler 190lcu rejenerasyon ortamına aktarılarak gelişimleri sağlanmıştır. Çalışmada anterlerden gelişen kallus sayısı, albino bitkicik sayısı, test tüplerine aktarılan yeşil bitkicik sayısı, toprağa aktarılan yeşil bitki sayısı ve spontan double haloid bitki sayıları belirlenmiştir. Yapılan önemlilik testi sonucunda melez popülasyonlarında incelenen tüm karakterlerde genotipler arasında istatistiki olarak önemli farklılık bulunmuştur. Yeşil bitkicik sayısı 1.0-25.25, kallus sayısı 128.75-2.25, tüplere aktarılan bitkicik sayısı 1.0-24.0 adet, toprağa aktarılan bitki sayısı ortalama olarak 0.00-17.50 adet, spontan double haploid bitki oranı \%0.00-55.00 arasında değişmiştir. En fazla seraya aktarılan bitki sayısı 17.30 adet ile Sagittario $x$ Pehlivan ve 9.50 adet ile Sagittario x Luzanovka melez popülasyonundan elde edilmiştir.

Anahtar Kelimeler: Anter, ekmeklik buğday, spontan double haploid, albino, kallus

\section{Obtaining of Doubled Haploid Plants from Bread Wheat (Triticum aestivum L.) Hybrid Populations by Anther Culture Technique}

\begin{abstract}
The objectives of this study were to determine for response rate of anther culture response in wheat hybrid populations In addition to this, response of seventy bread hybrid wheat populations in their early uninucleate period to anter culture were determined by using W14F medium. In the study, the number of calluses which developed from anthers, the number of albino plantlets, the number of green plantlets which transferred to test tubes, the number of green plants which transferred to the soil and the number of spontaneous double haploid plant were determined. Based on the results of significance test, the differences between genotypes in the hybrid populations for all investigated characters were found statistically significant. Green plantlets number, callus number, green plantless number in tubes, plant number in soil and spontaneous double haploid plant rate were changed between 1.0 to 25.25 unit, $128.75-2.25$ unit, $1.0-24.00$ unit, 0.0-17.50 unit and 55.00-0.00\%, respectively. The maximum number of plantlets, which transferred to the greenhouse, obtained from Sagittario x Pehlivan and Sagittario x Luzanovka hybrids population 17.30 units and 9.50 units, respectively.
\end{abstract}

Keywords: Anther, bread wheat population, spontaneous doubled haploid, albino, callus.

\section{Giriş}

nsan beslenmesi açısından yaşamsal öneme sahip olan buğdayda, verim ve kalite sorunlarının çözülmesi için genetik varyabilitenin sınırına yaklaşılmıştır. Son yüzyılda, klasik ıslah yöntemlerinden yararlanılarak üstün verimli ve kaliteli birçok çeşit geliştirilmesine rağmen başta hastalık ve zararılır olmak üzere bazı biyotik ve abiyotik çevresel baskılara karşı dayanıklılıkta istenilen sonuca ulaşılamamıştır (Özgen ve ark., 2000). Buğday ıslahında daha geniş varyabilitenin kısa sürede oluşturmak, ıslah süresinin etkinliğini artırmak ve ıslah süresini kısaltmak için yeni teknolojilere intiyaç duyulmaktadır. Bu teknolojiler içinde en yaygın olarak kullanılanlardan birisi double haploid teknolojisidir.

Haploidlerin kullanımının kazandırdığı en önemli avantajı, tam bir homozigotluğu elde etme olanağı sunmasıdır. Dihaploid hatların 
kullanılmasıyla genetik ve ıslah çalışmalarını yapmak hızlanmakta ve kolaylaşmaktadır. Anter kültürü, yaygın olarak desteklenen, buğdaydaki gelişmeler için homozigot double haploid hatlar üretmekte kullanılır ve bu son birkaç yıl içinde birçok ıslah programı arasında gitgide önemli bir teknik haline gelmiştir (Henry and De Buyser 1990).

$F_{1}$ çeşitlerinin geliştirilmesinde homozigot hatlar arasında üstün kombinasyon yeteneği verenlerin belirlenmesi yöntemi kullanıldığından, haploidinin hibrit çeşit ıslahında özel bir önemi bulunmaktadır. Dihaploid bitkilerden elde edilen saf hatlar $F_{1}$ çeşit ıslahında ebeveyn olarak kullanılabilir. Kombinasyon ıslahında da sonuca çok kısa sürede ulaşmayı sağlayan haploidi seviyesinde $F_{1}$ kademesindeki melez bitkilerden haploid çekerek farklı genotiplerde bulunan ve tek bir genotipte bulunması arzu edilen özelliklere sahip bitkiler kazanılması mümkündür. Özellikle yabancı döllenen bitkilerde heterozigoti oranı çok yüksek olduğundan bunlarda homozigot hatların elde edilebilmesi için 7-10 generasyon boyunca kendileme yapmak gerekmekte, kendine döllenen bitkilerde bile aynı amaç için 5-7 generasyon boyunca kendileme işlemine gerek duyulmaktadır ancak dihaploidizasyon yöntemi devreye girdiğinde homozigot hatlara tek generasyonda ulaşmak olasıdır.

Klasik buğdayın ıslahındaki mevcut sorunları aşabilmek için, doku kültürü ve biyoteknolojik yöntemlerden yararlanmak kaçınılmazdır. Genetik mühendisliği tekniklerinden yararlanılarak gen aktarmada önemli bir adım olan kallus oluşumu ve bitki rejenerasyonu çalışmalarında başarının büyük ölçüde genotip ile bağlı olduğu bilinmektedir (Şehirali ve Özgen 1998). Farklı araştırıcılar tarafından yapılan çalışmalarda anter kültürüne yanıtta halen genotipin özelliklerinin en önemli faktör olduğu ortaya konmuştur (Barbanas et al. 2001; Korkut ve ark. 2001, Korkut ve ark. 2003; Enginözü 2006; Ahmet ve Adak 2007; Foster et al. 2009; Saruer 2010; Salantur et al. 2011; Çay 2012).

Çalışmamızda farklı yönden üstün özelliklere sahip ekmeklik buğday ebeveynleri arasında oluşturulan melez popülasyonlarında anter kültürüne yanıtı yüksek genotiplerin belirlenmesi amaçlanmıştır.

\section{Materyal ve Yöntem}

Çalışmada, Namık Kemal Üniversitesi Ziraat Fakültesi Tarla Bitkileri Bölümü deneme alanında ekmeklik buğday genotipleri arasında yapılan melezlemelerden elde edilen $17 \mathrm{~F}_{2}$ popülasyonu [1.(Pehlivan $\mathrm{x}$ Krasunia), 2.(Seleinka x F85), 3.(Sagittario x Luzanovka), 4.(Golia x F85), 5.(F85 x Sana), 6. (Sagittario $x$ Sana), 7.(Sagittario $x$ Pehlivan), 8.(Golia $x$ Sana), 9.(F85 x Golia).10. (Pehlivan $x$ Krasunia//F85), 11.(Sagittario $x$ Golia), 12).(Sana $x$ Avustralya), 13.(Sana $x$ Sagittario) 14.(Pehlivan $x$ Bezostoja-1), 15.(Krasunia $x$ Pehlivan //Pehlivan), 16.(Sana x Bezostoja-1), 17.(Sagittario $x$ Krasunia)] materyal olarak kullanılmıştır.

$F_{1}$ generasyonunda bitkiler arasında seçim yapılamaması $F_{2}$ ve daha sonraki $F_{3}-F_{4}$ generasyonların bitki materyali olarak kullanılmasının uygun olduğu belirtilmiştir (Pauk et al. 2003). Bu yüzden araştırmamızda ıslah programında yer alan $F_{2}$ buğday popülasyonundan faydalanılmıştır. Çalışmamızda, deneme alanında yetiştirilen 17 adet $F_{2}$ popülasyonundan başaklanma döneminde çiçek tozları erken tek çekirdekli döneme geldiğinde bitki örnekleri alınmış ve 14 gün süresinde $4^{\circ} \mathrm{C}$ de soğuk odada bekletilmiştir. Daha sonra bu bitkilerden çıkartılan başaklar, içerisinde su $+\% 2$ 'lik sodyum hipoklorid ve birkaç damla damlatılmış Tween-20 bulunan solüsyonda 20 dakika süresince çalkalanarak steril edilmiştir. Yüzey sterilizasyonu yapılan bu başaklar steril kabin içerisinde 3-4 defa steril su ile yıkanmış, başakçıklar içerisindeki anterler steril pens yardımıyla çıkartılarak içersinde W14F başlangıç besi ortamı bulunan steril petri kaplarına transfer edilmiştir. Petri kapları önce 3 gün süresince $32^{\circ} \mathrm{C}$ 'de karanlık inkübatörde bekletilmiş, daha sonra kallus gelişimi için $28^{\circ} \mathrm{C}$ 'lik inkübatöre alınmıştır. Deneme, tesadüf parselleri deneme desenine göre 4 tekrarlamalı olarak yürütülmüştür. Bitki türlerine göre değişen sürelerde, genellikle 4-5 haftadan sonra anterlerden kallus gelişimi gözlenmiştir. Gelişen bu kalluslar yaklaşık $2 \mathrm{~cm}$ çapına ulaştıktan sonra içerisinde katı 190-2 Cu besi ortamı bulunan kaplara aktarılmış ve daha sonra 16 saat aydınlık $\left(250 \mathrm{mmol} \mathrm{s}^{-1} \mathrm{~m}^{-2}\right)-8$ saat karanlık fotoperiyottaki iklim odasına aktarıımıştır. Kalluslardan gelişen bitkicikler taze besi ortamı bulunan petri kapları ve test tüplerine aktarılmıştır. Yeterli gelişim gösterenler toprağa aktarılarak iklime alıştırma yapıldıktan sonra hasada kadar serada tutulmuşlardır.

Araştırmada, kallus sayısı (adet), albino bitki sayısı (adet), yeşil bitkicik sayısı (adet), test tüplerine aktarılan bitkicik sayısı (adet), toprağa 
Çizelge 1. Ekmeklik buğday melez popülasyonlarında elde edilen verilerde variyans analiz sonuçları Table 1. Variance analysis results of data obtained from bread wheat hybrid populations

\begin{tabular}{|c|c|c|c|c|c|c|c|c|c|c|c|c|}
\hline \multirow{2}{*}{ 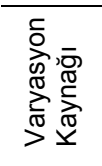 } & \multicolumn{2}{|c|}{$\begin{array}{l}\text { Kallus sayısı } \\
\text { (adet) }\end{array}$} & \multicolumn{2}{|c|}{$\begin{array}{l}\text { Albino bitki sayısı } \\
\text { (adet) }\end{array}$} & \multicolumn{2}{|c|}{$\begin{array}{c}\text { Yeşil bitkicik } \\
\text { sayısı } \\
\text { (adet) }\end{array}$} & \multicolumn{2}{|c|}{$\begin{array}{l}\text { Test tüplerine } \\
\text { aktarılan } \\
\text { bitkicik (adet) }\end{array}$} & \multicolumn{2}{|c|}{$\begin{array}{c}\text { Toprağa } \\
\text { aktarılan bitki } \\
\text { sayısı (adet) }\end{array}$} & \multicolumn{2}{|c|}{$\begin{array}{c}\text { Spontan double } \\
\text { haploid oranı } \\
(\%)\end{array}$} \\
\hline & $\begin{array}{l}\text { Kar. } \\
\text { Ort. }\end{array}$ & $\mathrm{F}_{\mathrm{Hes}}$ & $\begin{array}{l}\text { Kar. } \\
\text { Ort. }\end{array}$ & $\mathrm{F}_{\mathrm{Hes}}$ & $\begin{array}{l}\text { Kar. } \\
\text { Ort. }\end{array}$ & $\mathrm{F}_{\mathrm{Hes}}$ & $\begin{array}{l}\text { Kar. } \\
\text { Ort. }\end{array}$ & $\mathrm{F}_{\mathrm{Hes}}$ & $\begin{array}{l}\text { Kar. } \\
\text { Ort. }\end{array}$ & $\mathrm{F}_{\mathrm{Hes}}$ & $\begin{array}{l}\text { Kar. } \\
\text { Ort. }\end{array}$ & $\mathrm{F}_{\mathrm{Hes}}$ \\
\hline Genot & 4459.2 & $39.25^{\star *}$ & 926.60 & $52.13^{\star \star}$ & 133.31 & $25.47^{* *}$ & 124.98 & $23.97^{* *}$ & 64.46 & $51.80^{* *}$ & 329.23 & $407.2^{\star \star}$ \\
\hline Hata & 113.608 & & 17.77 & & 5.23 & & 5.21 & & 1.244 & & 0.81 & \\
\hline & 1151.36 & & 268.48 & & 37.25 & & 35.16 & & 17.83 & & 84.22 & \\
\hline
\end{tabular}

aktarılan bitki sayısı (adet) ve spontan doubled haploid oranı (\%) özellikleri incelenmiştir. Elde edilen verilerde tesadüf parselleri deneme desenine göre varyans analizi yapılmış, ortalamalar arasındaki farkların istatistiki anlamda önemlilikleri DUNCAN testi ile belirlenmiştir.

\section{Bulgular ve Tartışma}

Farklı bitkisel özelliklere sahip ekmeklik buğday genotipleri arasında yapılan melezleme sonucunda elde edilen $17 \mathrm{~F}_{2}$ ekmeklik buğday genotipinde yapılan anter kültürü çalışması sonucunda elde edilen değerlerde variyans analiz yapılmış ve elde edilen sonuçlar Çizelge 1 ' de verilmiştir

Yapılan variyans analizi sonucunda ekmeklik buğday melez popülasyonlarında incelenen kallus sayısı, albino bitki sayısı, yeşil bitkicik sayısı, test tüplerine aktarılan yeşil bitkicik sayısı, toprağa aktarılan yeşil bitkicik sayısı ve spontan doubled haploid oranları arasındaki farklılıklar 0.01 istatistiki olarak önemli bulunmuştur. Popülasyonlar arasındaki farklılığı ortaya koymak için yapılan önemlilik testi (DUNCAN) sonuçları Çizelge 2 de verilmiştir.

On yedi ekmeklik buğday melez popülasyonunda yapılan anter kültürü çalışması sonucunda incelenen karakterler yönünden popülasyonlar arasında önemli varyasyonlar gözlenmiştir. $F_{2}$ popülasyonlarında kallus sayısı 128.75- 2.25 adet arasında değişim göstermiştir. En fazla kallus sayısı 128.75 adet ile 12 numaralı melez popülasyonda elde edilmiş, bunu 88.00 adet ile $14 ; 64.00$ adet ile 8; 61.50 adet ile 7 ve 60.0 adet kallus sayısı ile 9 numaralı melez popülasyonlar izlemiştir. En az kallus sayısı ise 2.25 adet ile 10 numaralı melez popülasyonunda elde edilmiş, bunu 4.50 adet ile 17 numaralı popülasyon, 7.50 adet ile 5 numaralı popülasyonlar izlemişlerdir. Anter kültürü çalışmalarında yüksek yanıt elde edilen yeşil bitki sayısı ifade ile edilmektedir. Ancak birçok çalışmada yeşil bitki oranı yanında çok sayıda albino bitki üretimi de olmaktadır. Düşük sayıda ya da olmaması istenen albino bitki sayısı yönünden ekmeklik buğday melez popülasyonları incelendiğinde, albino bitki sayısının 56.25-0.00 adet arasında değiştiği belirlenmiştir. En fazla albino bitki üretimi en fazla kallus elde edilen 12 numaralı popülasyondan (56.25 adet) elde edilmiştir. Bunu yine en fazla kallus elde edilen 14 numaralı populasyon 42.50 adet albino bitkicik ile izlemiştir. 27.50 adet albino bitkicik ile 9 numaralı popülasyon ve 23.75 adet ile 16 numaralı populasyon ve 15.00 adet ile 8 numaralı populasyonlar bu iki populasyonu izlemiştir. En düşük kallus üretimi veren 17 numaralı popülasyondan hiç albino bitkicik üretimi olmamıştır. Bunu 1 adet albino bitkicik ile 10 ve 3 numaralı popülasyonlar, 1.25 ve 1.50 adet albino bitkicik ile 5 ve 13 numaralı popülasyonlar izlemişlerdir.

Anter kültürüne yanıtta kalluslardan elde edilen yeşil bitkicik sayısı en önemli kriterdir. Dört tekrarlamalı olarak yürütülen çalışmamızda yeşil bitkicik sayısı 25.25-1.00 adet arasında değişim göstermiştir. En fazla yeşil bitkicik yanıtı kallus üretiminde 4 . sırada yer alan 7 numaralı popülasyonda 25.25 adet ile olmuştur. Bunu kallus üretimi yönünden orta sıralarda yer alan 3 numaralı popülasyon 14.50 adet ile izlemiştir. 8.50 adet yeşil bitki sayısı ile üçüncü sırada yer alan 8 numaralı genotip kallus sayısı yönünden de 3. sırada yer almıştır. Yine kallus üretimi yönünden orta sıralarda yer alan 15 numaralı popülasyon ve 2 numaralı popülasyonlar bunları izlemişlerdir. Kallus üretimi yönünden ilk sırada olan 12 ve 14 numaralı genotipler ise daha sonraları sıralanmışlardır. En az yeşil bitkicik üretimi ise 1.0 adet ile 17 ve 10 numaralı popülasyonlarda olmuştur. Bunları 1.25 adet ile 5 numaralı popülasyon, 3.25 adet ile 14 ve 9 numaralı popülasyonlar izlemişlerdir. Elde edilen sonuçlar yeşil bitkicik sayısının kallus sayısı ile ilişkili olmadığını yani kallus sayısı yüksek olan genotiplerden yüksek yeşil bitki yanıtı elde edilemeyebileceğini göstermektedir. 

by Anther Culture Technique"

Çizelge 2. Ekmeklik buğday melez popülasyonlarında ortalama değerler ve önemlilikleri Table 2. Averages and significances of bread wheat hybrid populations

\begin{tabular}{|c|c|c|c|c|c|c|c|c|c|c|c|}
\hline \multicolumn{2}{|c|}{$\begin{array}{l}\text { Kallus sayısı } \\
\text { (adet) }\end{array}$} & \multicolumn{2}{|c|}{$\begin{array}{l}\text { Albino bitki } \\
\text { sayısı } \\
\text { (adet) }\end{array}$} & \multicolumn{2}{|c|}{$\begin{array}{c}\text { Yeşil bitkicik } \\
\text { sayısı(adet) }\end{array}$} & \multicolumn{2}{|c|}{$\begin{array}{l}\text { Test tüplerine } \\
\text { aktarılan } \\
\text { bitkicik sayısı } \\
\text { (adet) }\end{array}$} & \multicolumn{2}{|c|}{$\begin{array}{c}\text { Toprağa } \\
\text { aktarılan bitki } \\
\text { sayısı(adet) }\end{array}$} & \multicolumn{2}{|c|}{$\begin{array}{l}\text { Spontan double } \\
\text { haploid oranı(\%) }\end{array}$} \\
\hline $\begin{array}{l}\text { Pop } \\
\text { No }\end{array}$ & $\begin{array}{c}\text { Ortalama } \\
\text { değerler }\end{array}$ & $\begin{array}{l}\text { Pop } \\
\text { No }\end{array}$ & $\begin{array}{l}\text { Ortalama } \\
\text { değerler }\end{array}$ & $\begin{array}{l}\text { Pop } \\
\text { No }\end{array}$ & $\begin{array}{c}\text { Ortalama } \\
\text { değerler }\end{array}$ & $\begin{array}{l}\text { Pop. } \\
\text { No }\end{array}$ & $\begin{array}{l}\text { Ortalama } \\
\text { değerler }\end{array}$ & $\begin{array}{l}\text { Pop } \\
\text { No }\end{array}$ & $\begin{array}{l}\text { Ortalama } \\
\text { değerler }\end{array}$ & $\begin{array}{l}\text { Pop. } \\
\text { No }\end{array}$ & $\begin{array}{l}\text { Ortalama } \\
\text { değerler }\end{array}$ \\
\hline 12 & $128.75 \mathrm{a}$ & 12 & $56.25 \mathrm{a}$ & 7 & $25.25 a$ & 7 & $24.00 \mathrm{a}$ & 7 & $17.50 \mathrm{a}$ & 15 & $55.00 \mathrm{a}$ \\
\hline 14 & $88.00 a b$ & 14 & $42.50 \mathrm{ab}$ & 3 & $14.50 \mathrm{ab}$ & 3 & $13.75 a b$ & 3 & $9.50 \mathrm{~b}$ & 6 & $52.00 \mathrm{a}$ \\
\hline 8 & 64.00 bc & 9 & $27.50 \mathrm{bc}$ & 8 & 8.50 bc & 8 & 9.50 bc & 8 & $6.50 \mathrm{bc}$ & 1 & $51.75 \mathrm{a}$ \\
\hline 7 & $61.50 \mathrm{bcd}$ & 16 & $23.75 \mathrm{~cd}$ & 15 & $8.50 \mathrm{bc}$ & 15 & $7.25 \mathrm{bcd}$ & 15 & $5.00 \mathrm{~cd}$ & 3 & $45.25 b$ \\
\hline 9 & $60.00 \mathrm{bcd}$ & 8 & $15.00 \mathrm{~cd} \epsilon$ & 2 & $7.00 \mathrm{bc}$ & 6 & 5.50 cde & 6 & $4.75 \mathrm{cde}$ & 7 & $40.75 c$ \\
\hline 1 & 50.50 cde & 1 & $11.25 \mathrm{det}$ & 12 & $6.00 \mathrm{~cd}$ & 12 & $5.50 \mathrm{cde}$ & 12 & $4.75 \mathrm{cde}$ & 14 & $39.50 \mathrm{~cd}$ \\
\hline 16 & 49.00 cde & 15 & $9.00 \mathrm{fgh}$ & 6 & $5.50 \mathrm{~cd}$ & 2 & $5.25 \mathrm{cde}$ & 2 & $4.25 \mathrm{c}-\mathrm{f}$ & 12 & $37.75 d$ \\
\hline 15 & $37.50 \mathrm{~d}-\mathrm{g}$ & 2 & $8.75 \mathrm{fgh}$ & 1 & $5.25 \mathrm{~cd}$ & 1 & $4.50 \mathrm{cde}$ & 1 & $3.25 \mathrm{~d}-\mathrm{g}$ & 2 & $37.25 \mathrm{~d}$ \\
\hline 3 & $32.75 \mathrm{~d}-\mathrm{g}$ & 7 & $6.25 \mathrm{fgh}$ & 4 & $4.50 \mathrm{~cd}$ & 13 & $4.25 \mathrm{cde}$ & 13 & $2.50 \mathrm{~d}-\mathrm{g}$ & 10 & $33.25 \mathrm{e}$ \\
\hline 6 & 25.00 e-h & 11 & $5.50 \mathrm{fgh}$ & 11 & $4.25 \mathrm{~cd}$ & 4 & $4.00 \mathrm{cde}$ & 4 & $2.50 \mathrm{~d}-\mathrm{h}$ & 17 & $33.25 \mathrm{e}$ \\
\hline 2 & 24.00 e-h & 6 & $4.50 \mathrm{fgh}$ & 13 & $4.25 \mathrm{~cd}$ & 11 & 3.75 cde & 11 & $2.50 \mathrm{~d}-\mathrm{h}$ & 11 & $33.00 \mathrm{e}$ \\
\hline 11 & $20.00 \mathrm{fgh}$ & 4 & $3.50 \mathrm{gh}$ & 16 & $3.50 \mathrm{~cd}$ & 16 & $3.25 \mathrm{de}$ & 16 & 2.00 efgh & 4 & $30.00 \mathrm{f}$ \\
\hline 4 & $16.00 \mathrm{fgh}$ & 13 & $1.50 \mathrm{gh}$ & 9 & $3.25 \mathrm{~cd}$ & 9 & $2.75 \mathrm{de}$ & 9 & $1.50 \mathrm{fgh}$ & 16 & $30.00 \mathrm{f}$ \\
\hline 13 & $12.25 \mathrm{fgh}$ & 5 & $1.25 \mathrm{gh}$ & 14 & $3.25 \mathrm{~cd}$ & 14 & $2.50 \mathrm{de}$ & 14 & $1.00 \mathrm{gh}$ & 9 & $28.75 f$ \\
\hline 5 & $7.50 \mathrm{gh}$ & 3 & $1.00 \mathrm{gh}$ & 5 & $1.25 \mathrm{~d}$ & 5 & $1.00 \mathrm{e}$ & 5 & $1.00 \mathrm{gh}$ & 8 & $26.50 \mathrm{~g}$ \\
\hline 17 & $4.50 \mathrm{~h}$ & 10 & $1.00 \mathrm{gh}$ & 10 & $1.00 \mathrm{~d}$ & 10 & $1.00 \mathrm{e}$ & 10 & $1.00 \mathrm{gh}$ & 13 & $25.00 \mathrm{~g}$ \\
\hline 10 & $2.25 \mathrm{~h}$ & 17 & $0.00 \mathrm{~h}$ & 17 & $1.00 \mathrm{~d}$ & 17 & $1.00 \mathrm{e}$ & 17 & $0.00 \mathrm{~h}$ & 5 & $0.00 \mathrm{~h}$ \\
\hline $\mathrm{HKO}$ & 113.608 & & 17.774 & & 5.234 & & 5.214 & & 5.214 & & 0.809 \\
\hline
\end{tabular}

Test tüplerine ve toprağa aktarılan bitki sayısı anter kültüründe başarı oranını etkileyen bir faktördür. Test tüplerine ve toprağa aktarım sırasında bazı bitkicikler yaşam özelliklerin yitirebilmektedir. Test tüplerine ve toprağa aktarılan bitki sayıları $24.00-1.00$ ve $17.50-0.00$ adet arasında değişmiştir. Elde edilen değerlerden de görülebileceği gibi bazı kombinasyonlarda özellikle toprağa aktarım esnasında bazı bitkiler ölmüştür. Test tüplerine aktarılan bitki sayısı yönünden 24.00 adet ile 7 numaralı popülasyon ilk sıra yer almış, bunu 13.75 adet ile $3,6.50$ adet ile $8,5.0$ adet ile 15 , 5.50 adet ile 6 ve 12 numaralı genotipler izlemişlerdir. En düşük ise 1.00 adet bitkicik ile 17,10 ve 5 numaralı popülasyonlarda elde edilmiştir. Toprağa aktarılan bitkicik sayısı yönünden ilk sırada 7 adet bitkicik kaybı olan 7 numaralı popülasyon (17.50 adet) yer almış, bunu 9.50 adet ile $3,6.50$ adet ile 8,5 adet ile $15,4.75$ adet ile ise 6 ve 12 numaralı popülasyonlar izlemişlerdir. En az bitkicik sayısı ise 0.00 adet ile 17 numaralı popülasyonda olmuş, bunu 1.00 adet ile 10,5 ve 14 numaralı popülasyonlar izlemişlerdir.

Anter kültüründe elde edilen bitkilerin haploid ya da spontan doubled haploid oranları hem çalışmaların hızlı yürütülmesi açısından hem de ekonomik açıdan önemlidir. Doubled haploid bitkilerin fazla olması kromozom katlaması çalışmaları için ek zaman harcamayı ve de masrafı önlemektedir. Çalışma da ekmeklik buğday popülasyonlarında spontan doubled haploid bitki oranının \% 55.0-0.00 arasında değiştiği belirlenmiştir. En yüksek spontan doubled haploid bitki oranı $\% 55.00$ ile 15 numaralı popülasyondan elde edilmiş, bunu $\% 52.00$ ile 6 numaralı popülasyon, \% 51.75 ile 1 numaralı popülasyon izlemişlerdir. En yüksek doubled haploid bitki elde edilen genotipler yeşil bitki ve albino bitki sayısı yönünden ilk sıralarda yer almamışlardır. Bu da bu genotiplerin sahip oldukları genotipik yapılarının diğer ifade ile melez kombinasyonlarının ayrıntılı incelenmesi gerektiğini ortaya koymaktadır. En az spontan doubled haploid bitki sayısı hiç bitki üretilmeyen 5 numaralı popülasyonda olmuş, bunu 13,8 , ve 9 numaralı popülasyonlar izlemişlerdir.

\section{Sonuç}

Elde edilen verilerin değerlendirilmesi sonucunda, ekmeklik buğday melez popülasyonlarında oluşturulan anaç kombinasyonlarının kallus, albino bitki, yeşil bitkicik sayısı ve spontan doubled haploid bitki oranı yönünden oldukça önemli olduğu görülmüştür. Double haploid bitki elde etmek amacıyla yapılacak çalışmalarda ebeveyn kombinasyonlarının seçiminin en önemli basamak olduğu sonucuna varılmıştır. Araştırmamızda, 15 (KrasuniaxPehlivan //Pehlivan), 6 (SagittarioxSana) ve 1 (PehlivanxKrasunia) numaralı popülasyonlar anter kültürüne yanıtı yüksek popülasyonlar olarak belirlenmiştir. 


\section{Kaynaklar}

Ahmet H. ve Adak M.S., 2007. Irak'ta yetiştirilen bazı ekmeklik buğday çeşitlerinde kallus oluşumu ve bitki rejenerasyonu. Tarım Bilimleri Dergisi, 13(3): 285-291.

Barnabas E., Szakacs E., Karsai I. and Bedö Z., 2001. In vitro androgenesis of wheat. From Fundamentals to Practical Application, 119: 211-216.

Çay F., 2012. Bazı Buğday Melez Popülasyonlarının Anter Kültürüne Yanıtları. (Yüksek Lisans Tezi). Namık Kemal Üniversitesi, Fen Bilimleri Enstitüsü, s. 64.

Enginözü M., 2006. Donör Bitkilerin Yetişme Koşulları ve Farklı Kültür Sıcaklıklarının Ekmeklik Buğday (Triticum aestivum L.) Anter Kültüründe Haploid Bitki Rejenerasyonuna Etkileri Üzerine Bir Araştırma. (Yüksek Lisans Tezi). Çukurova Üniversitesi, Fen Bilimleri Enstitüsü.

Foster B.P., Touraev A. and Jain S.M., 2009. Advances in Haploid Production in Higher Plants, 12110.

Henry Y. and De Buyser J., 1990. Wheat Anther Culture: Agronomic Performance of Doubled Haploid Lines and The Release of A New Variety "Florin". Biotechnology in Agriculture and Forestry, Volume 13, Ed: Y.P.S. BAJAJ Springer-Verlag, Berlin-Heidelberg.
Korkut K.Z., Başer I., Turhan H. ve Bilgin O., 2001 Yerli Ve Yabancı Kökenli Ekmeklik Buğday Çeşit Ve Hatlarında Haploid ve Dihaploid Genotiplerin Elde Edilme Olanakları. TÜAF232. Tekirdağ.

Korkut K.Z., Başer İ., Turhan H. ve Bilgin O., 2003. Androgenetic plant production in local foreign bread wheat genotypes. Turkish Journal Of Field Crops, 8:1, 9-14.

Özgen M., Adak M.S., Söylemezoğlu G. ve Ulukan H., 2000. Bitkisel gen kaynaklarının koruma ve kullanımında yeni yaklaşımlar. Türkiye Ziraat Mühendisligi V. Teknik Kongresi, 259289, Ankara.

Pauk J., Mihaly R. and Puolimatka M., 2003. Protocol for Wheat (Triticum aestivum L.) Anther Culture. Doubled Haploid Production in Crop Plants, 59-64.

Salantur A., Yazar S., Dönmez E. ve Akar T., 2011. Kışlık ekmeklik buğday F2 popülasyonlarının anter kültüründe bitki rejenarasyonuna tepkisinin belirlenmesi, Tarla Bitkileri Merkez Araştırma Enstitüsü Dergisi, 2011, 20 (1): 1521.

Sarıer S.Y., 2010. Mısır Bitkisinde Anter Kültürü Olanakları Üzerine Araştırmalar. (Yüksek Lisans Tezi). Namık Kemal Üniversitesi, Fen Bilimleri Enstitüsü, s.56. 